\title{
Em Busca de Soluções para os Problemas da Sociedade
}

Searching for Solutions to the Problems of Society

\section{A Pró-Reitoria de Cultura e Extensão Universitária da USP é formada por} um conjunto de doze órgãos, treze programas, quatro câmaras, quinze núcleos de apoio à cultura e extensão, ações de fomento e financiamento a projetos e 1200 bolsas para estudantes de graduação pelo Aprender com Cultura e Extensão. Além disso, mantém importantes programas de atendimento à sociedade, como o USP e as Profissões, Universidade Aberta à Terceira Idade e Giro Cultural USP.

Administrar este universo diversificado de atividades é o desafio da socióloga Maria Arminda do Nascimento Arruda em sua segunda gestão à frente da Pró-Reitoria de Cultura e Extensão Universitária. Nesta entrevista, a comissão editorial da Revista de Cultura e Extensão USP conversou com a pró-reitora sobre importância da cultura e extensão universitária e os desafios para esta área.
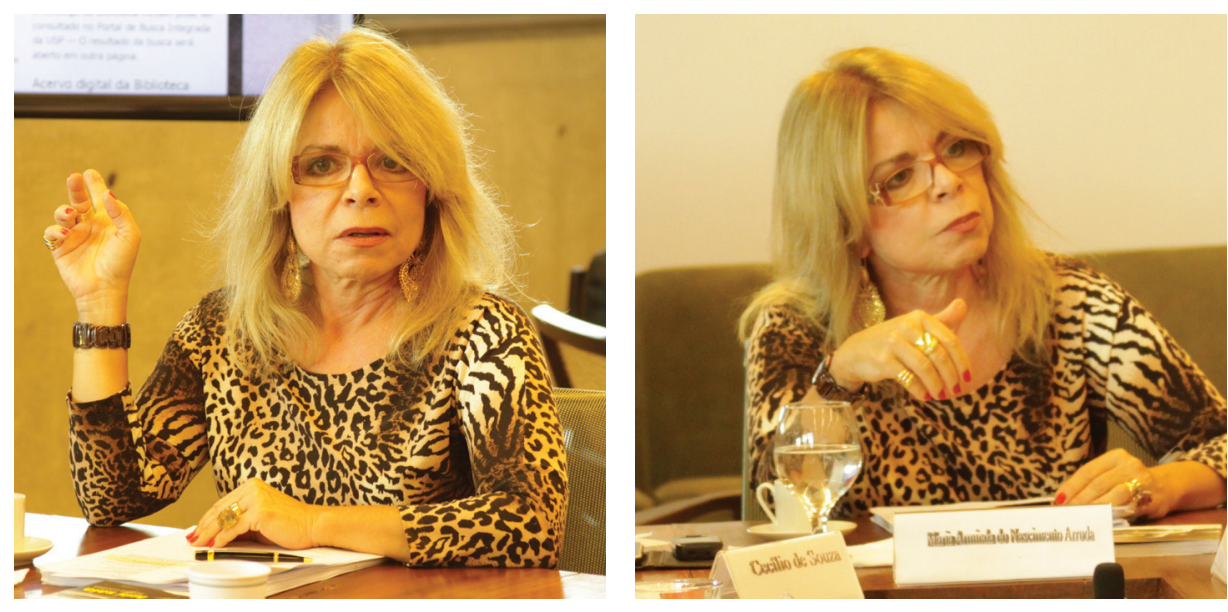

Rev. Cult. e Ext. USP, São Paulo, n. 12, p.11-17, nov. 2014 DOI: http://dx.doi.org/10.11606/issn.2316-9060.v12i0p11-17
Diana Helena de

Benedetto Pozzi,

BRUNO ROBERTO

Padovano, Suzana

Helena de Avelar

Gomes, Waldenyr

Caldas e Verônica

Cristo

Universidade de São Paulo. Pró-Reitoria de Cultura e Extensão Universitária, São Paulo, Brasil

Maria Arminda do Nascimento Arruda é professora titular da Faculdade de Filosofia, Letras e Ciências Humanas e Pró-Reitora de Cultura e Extensão Universitária da Universidade de São Paulo. 
Bruno Roberto Padovano - Qual a importância da cultura numa visão estratégica de universidade, fortalecendo sua integração à sociedade como um todo? Maria Arminda do Nascimento Arruda - Em primeiro lugar, a cultura e a extensão, entendidas como uma única área de gestão, têm uma importância igual às outras; enquanto tal, porque não existe desigualdade do ponto de vista organizacional. Dessa maneira, a existência de uma Pró-Reitoria de Cultura e Extensão é, por si só, um reconhecimento da importância desta área. Todavia, isso é suficiente? Não, definitivamente não é suficiente.

Nós sabemos que se algo acontece na Universidade do ponto de vista orçamentário, por exemplo, essa é uma área sempre muito atingida. É difícil dizer se é a área mais atingida, mas, com certeza, é a primeira a sofrer em um momento de crise. Isso significa que, embora a cultura e extensão tenham uma posição igualitária às outras, ela não é reconhecida como tal. E por que isso acontece? Essa é a grande questão que nós temos que enfrentar. Vou começar pela área da cultura, que, naturalmente, é central.

A cultura dá uma noção NUM MOMENTO EM QUE A USP ESTÁ PASSANDO POR QUESTIONAMENTOS TÃO SÉRIOS, ACREDITO QUE A MANEIRA MAIS EFICAZ E MAIS RÁPIDA DE REFAZERMOS A IMAGEM DA UNIVERSIDADE É POR INTERMÉDIO DA CULTURA - DA MÚSICA, DAS EXPOSIÇÕES, DOS EVENTOS CULTURAIS, ENFIM, DE TODAS ESSAS EXPRESSÕES QUE TÊM VISIBILIDADE NA SOCIEDADE. do todo porque envolve o

conjunto da vida humana. A pesquisa científica e a valorização da ciência são, por exemplo, frutos de uma cultura. Tanto as culturas atuais quanto as do passado valorizavam outras formas de pensar o mundo. Veja, por exemplo, no período clássico, quando o pensamento filosófico ordenava a concepção de mundo. Mas o universo da história é sempre mutável e o Ocidente moderno passou a valorizar um certo tipo de conhecimento ligado à pesquisa empírica. É claro que esse é um tema muito espinhoso, que merece em si mesmo uma reflexão. Então, eu só adianto rapidamente algumas ideias.

A primeira delas é que isso faz parte da laicização, da racionalização e de formas de individuação, fenômeno que começa no século XVIII. É quando a religião deixa de ordenar a explicação do mundo, fato que está ligado a outros processos históricos mais fundos que não cabe aqui analisar. Agora, quem imagina que a cultura é secundária não é capaz de perceber nada, absolutamente nada. Não só no que diz respeito à produção humana, mas também não é capaz de perceber nada sobre o mundo contemporâneo.

Todo ato humano, qualquer que seja, é cultural - o gesto, a maneira como nos posicionamos, até mesmo os nossos corpos e as nossas posturas -, tudo é cultural e social. É possível, e há muitos estudos que mostram isso, falar sobre a posição social de uma pessoa, sobre o seu lugar no mundo, apenas olhando os seus gestos.

Mas, se a cultura é tudo, o que ela seria particularmente? Poderia se dizer que algo que seja tudo não é nada. Há uma definição de Friedrich Nietzsche que diz que todos os fenômenos que se referem ao todo dificilmente são conceitualizados. Ora, o mundo das ciências é o mundo do conceito, e o que escapa à conceituação estrita parece secundário.

No entanto, nós podemos operar com alguns significados particulares de cultura. É por isso que nós trabalhamos com algumas divisões de cultura, seja cultura erudita, cultura artística, literária, cultura popular. A cultura, no sentido mais geral, é aquela que ordena os nossos valores, as nossas visões de mundo e que permeia as nossas ações. Não existe nenhuma ação humana, nenhuma ação social que não esteja permeada pela cultura. Senão, como nós estaríamos aqui conversando? Nós temos algum universo comum o que permite esse entendimento. Se você falasse uma língua desconhecida por mim, nós não teríamos entendimento nenhum. Mas eu sei que você não só fala a mesma língua que a minha - e a língua é uma construção cultural - como eu também sei o que esperar de você e você sabe o que esperar de mim. Esse assentamento de concepções e 
expectativas que permeiam as relações entre as pessoas é dado pela cultura.

A segunda coisa é que o mundo contemporâneo tornou-se o mundo da cultura. Isso porque tudo virou cultura e tudo virou culturalizável: os nossos objetos de consumo são símbolos, são linguagens de processos sociais e culturais. $\mathrm{O}$ mundo global é o mundo da cultura que se homogeneíza, que nós temos, sobretudo, mas não exclusivamente, por intermédio da informação, da internet, das redes. É um mundo que tende a construir uma homogeneidade. É claro que, a despeito disso, ele não aplastou tudo. As particularidades regionais e culturais persistem. É interessante perceber que esse mundo homogêneo convive também com reivindicações identitárias particularistas. Nesse sentido, as identidades estão fracionadas.

Num momento em que a USP está passando por questionamentos tão sérios, acredito que a maneira mais eficaz e mais rápida de refazermos a imagem da Universidade é por intermédio da cultura - da música, das exposições, dos eventos culturais, enfim, de todas essas expressões que têm visibilidade na sociedade. E a USP é um lugar privilegiado para isso, pois detém um patrimônio cultural muito rico no que diz respeito a acervos museológicos e a acervos de uma maneira geral. São iniciativas diversas na área da cultura: há órgãos culturais e institutos de cultura especializados que praticamente nenhuma universidade do mundo tem.

Verônica Cristo - Em certo momento de sua história, observamos que a Universidade passou a incorporar diversos acervos...

MADNA - E criou outros. E o que isso quer dizer? Eu me dediquei ao assunto em um projeto importante no campo das ciências sociais no Brasil, sobre a história cultural de São Paulo. O projeto foi desenvolvido pelo IDESP [Instituto de Estudos Econômicos Sociais e Políticos de São Paulo], com coordenação do professor Sérgio Miceli, mas que congregou vários pesquisadores. Neste projeto, eu tratei particularmente da história da Universidade de São Paulo.

Desde a sua criação, a USP foi um projeto ligado à ideia de que era preciso modernizar a cultura de São Paulo. E, nesse processo, pode-se dizer que a Universidade teve um êxito espetacular: ela vertebrou o sistema cultural e intelectual de São Paulo e, portanto, do Brasil, à medida em que se tornou a mais importante universidade brasileira. É por isso que a USP possui esses acervos. Mesmo aquelas instituições que não tinham nascido com a Universidade vieram para o seu abrigo. E a USP tem uma responsabilidade pública em relação a isso.

Então, cada vez que eu vejo descaso com essa área, o que está se tratando com descaso é a própria Universidade de São Paulo. Parece que essas concepções limitadas do que seja pesquisa - que felizmente têm sido afastadas - é que puseram essa área num lugar secundário. E isso não é aceitável, pois expressa uma visão equivocada do que sejam as sociedades contemporâneas, do que seja o projeto uspiano e do que seja a construção da própria ciência em São Paulo.

É difícil lidar com a cultura. Lidar com a cultura é lidar com a diversidade. E é difícil reconhecer essa diversidade. A ciência experimental lida, sobretudo, com pesquisas em laboratórios em que todo o ambiente é controlado. Lidar com a cultura não é assim, não há controle. A cultura tem sempre essa dimensão resistente. Não foi por um acaso que os nazistas perseguiram essa área. O Goebbels [Joseph Goebbels, político alemão e Ministro da Propaganda na Alemanha nazista] tinha uma frase que se tornou antológica e, mesmo deslocada do seu contexto, serviria aqui. A frase era: "Todas as vezes que ouço a palavra cultura tenho vontade de puxar o revólver". Essa frase terrível mostra que a cultura tem uma dimensão resistente crítica e isso é parte dela. $\mathrm{E}$ não tem jeito. A cultura existe para pensar o mundo no sentido global e nós vivemos um mundo global.

BRP - Sob esta mesma visão, qual seria a importância da extensão?

MADNA - A extensão não se separa da cultura uma vez que a compreensão de que a Universidade tem que ter projetos de extensão - essa dimensão extrovertida da universidade, que se volta para o mundo e para a sociedade - é também parte do mundo 
contemporâneo e é cada vez mais acentuado.

Não é por um acaso que todo ramo do pensamento que trata das concepções da cidadania, especialmente a ciência política, está discutindo algo que parecia impensável há pouco tempo. Nós, que discutimos a cidadania política e a cidadania social, agora discutimos a cidadania cultural. A noção da cidadania não se realiza sem acesso à cultura e sem acesso à produção intelectual e científica da sociedade. Por isso que a difusão da ciência como processo de educação e de direito é tão central hoje. Essa é uma dimensão da cultura também, uma vez que os processos-cidadãos não estão desprendidos do direito à cultura. Por isso o direito cultural.

A Universidade tem que fazer extensão, especialmente por ser uma universidade pública, porque ela precisa dizer à sociedade a que veio. A pesquisa experimental leva um longo tempo de maturação e é natural que assim seja: o avanço implica tempo em todas as áreas, inclusive nas ciências humanas. No entanto, a sociedade tem urgência de formação e incorporação nós estamos vivendo sob o signo de incorporação social -, tem urgência em saber o que uma universidade pública faz e como utiliza os seus recursos. E nós temos que dar um retorno.

E como a extensão aparece? Do ponto de vista de projetos culturais, pedagógicos e científicos, a difusão da ciência é diferente da difusão das artes e da cultura, até mesmo no oferecimento de soluções para problemas sociais candentes, o que é central. Como a Universidade pode, com as suas pesquisas, fazer avançar aquelas dimensões que são centrais para a sociedade? Do ponto de vista dos direitos, como a Universidade pode ajudar a discutir qual é o universo dos direitos? Do ponto de vista da ciência experimental, como a Universidade pode construir e revelar para a sociedade as pesquisas que ela fez e que vão resultar em medicamentos ou em procedimentos de várias ordens? Do ponto de vista social, mais estrito, como a Universidade pode responder às demandas da sociedade? A Universidade possui equipamentos e pessoal para tal e ela tem uma responsabilidade em relação à sociedade. Nesse sentido, como ela pode equacionar problemas variados da vida social? Por exemplo, o que a Universidade pode oferecer à sociedade para a solução desse caos urbano das grandes metrópoles? Ainda, que soluções oferecer para a construção de moradias populares funcionais e baratas a fim resolver o problema da locomoção, do tráfico, a problemática da droga e dos moradores de rua, ou para maior qualificação dos professores da rede pública paulista e, além disso, para um ensino público de mais qualidade?

Não devemos nos esquecer que apenas $1 \%$ dos professores da rede pública paulista é formado na Universidade de São Paulo e a sociedade tem direito de nos questionar sobre o que nós estamos fazendo com as nossas carreiras voltadas para formação de professores. Uma Universidade com este padrão deve, com certeza, formar professores bem qualificados. E a extensão agiliza a formação profissional em vários campos importantíssimos.

A extensão é também o lugar no qual questões de ponta são refletidas. Por exemplo, a questão do meio ambiente, do problema da energia, da ética na pesquisa. Isso só uma universidade de qualidade pode fazer e nós não estamos fazendo. $\mathrm{O}$ que eu quero dizer é que a cultura e a extensão criam um todo porque a própria compreensão da necessidade da extensão, do direito à extensão, do direito ao conhecimento e à cultura, do direito a que uma instituição pública tenha agilidade para equacionar questões da sociedade, tudo isso é fruto de uma cultura que se democratizou. 
Waldenyr Caldas - Como fica, após a greve, a politica da Pró-Reitoria de Cultura e Extensão Universitária para os projetos pensados anteriormente, em face da restrição orçamentária?

MADNA - A Pró-Reitoria de Cultura e Extensão é um lugar privilegiado para repensar a imagem da USP e para ajudar a tornar sua imagem translúcida de novo. Isso quer dizer que o programa da Pró-Reitoria apresentou um conjunto de iniciativas voltadas para recuperar essa imagem e retecer as nossas relações internas e com a sociedade, que estão muito dilaceradas. Em alguns momentos, eu tinha a impressão de que nós estávamos vivendo uma espécie de estado da natureza, de guerra de todos contra todos.

Então, o que é possível fazer? Primeiramente, uma de nossas diretrizes de ação, mais instrumental, diz respeito à descentralização e à desburocratização dos processos internos, o que já tem sido feito desde o início da gestão. Queremos conferir mais funções às Comissões de Cultura e Extensão das unidades, que serão organismos com grande autonomia, enquanto que o Conselho de Cultura e Extensão será um órgão de formulação de políticas públicas e não de burocracia.

Além disso, nosso programa está centrado em quatro eixos. O primeiro eixo é o dos projetos de residências de profissionais de destaque no campo das artes, das profissões e no campo de pós-doutorados. São projetos de professores que congregam estudantes e funcionários e deverão ter como efeito, por exemplo, no campo das artes, uma peça ou uma obra na qual os estudantes também estejam envolvidos.

Outro eixo é a agência de direitos, criada para discutir o temário dos direitos aqui na Universidade de São Paulo. Não podemos esquecer que parte da nossa crise tem a ver com uma visão equivocada de direitos; usa-se a formulação "eu tenho direito a..." como se os direitos fossem uma dimensão exclusivista. Não se tratam de verdadeiros direitos. Isso é individualismo possessivo, para lembrar a expressão de um grande autor, espaço Macpherson, ou então um narcisismo enorme, que é um fenômeno muito contemporâneo, chamado por Freud de narcisismo das pequenas diferenças.
Dessa maneira, nossa proposta é discutir os direitos e estimular a USP a buscar parcerias com instituições públicas e sociedade civil. Ao mesmo tempo, queremos promover um amplo debate, um amplo processo de formação no campo dos direitos. Por isso, a proposta da agência é para que a USP volte a ser um instrumento fundamental de diálogo com as políticas públicas da área.

O terceiro eixo é um conjunto de cursos nos temas mais sensíveis da sociedade; temos, por exemplo, a ética na pesquisa - o que eu chamei genericamente de limites do humano -, que irá discutir os experimentos biológicos, o meio ambiente, energia, etc. São temas centrais que as universidades brasileiras não estão discutindo e, se não começarem a fazê-lo, temo que vamos destruir o mundo.

Quanto ao Programa de Editais, a edição de 2012 já está praticamente encerrada, enquanto que a edição em 2013 está em andamento, uma vez que os recursos não foram atribuídos ainda por causa dos cortes orçamentários. No próximo dia 27 de novembro iremos realizar um seminário para avaliar e verificar os resultados alcançados pelo programa. Afinal, não podemos lançar uma nova edição quando temos um edital parado e outro ainda sem avaliação.

VC - Qual o impacto da restrição orçamentária para a Pró-Reitoria? Algo deixará de ser feito por conta disso? MADNA - Diferentemente das outras pró-reitorias, a Pró-Reitoria de Cultura e Extensão Universitária precisa de muitos recursos para o desenvolvimento de seus projetos e iniciativas. A Graduação tem um fluxo contínuo de atividades. A Pós-Graduação conta com recursos dominantemente externos, que são as bolsas distribuídas por agências de fomento, tais como a Capes, CNPq, FAPESP, etc. A Pesquisa também conta com as agências de financiamento, mas não a Cultura e Extensão. Isso porque as agências ainda têm um entendimento equivocado do que seja esta área, mas eu acredito que isso tem mudado. Tenho trabalhado muito nesse sentido.

Dessa maneira, a Cultura e Extensão naturalmente sofre mais, porque sem recursos não é possível organizar uma Virada Científica [evento de 
divulgação científica realizado por várias unidades de ensino da USP, num total de mais de 100 atividades oferecidas gratuitamente ao público nos dias 11 e 12 de outubro], uma Feira de Profissões da USP [evento que, em sua última edição, em agosto, reuniu quase 50 mil pessoas no Parque CienTec], que tem um papel decisivo na ampliação do número de inscritos da rede pública no vestibular da USP.

Nesse momento, o que nós procuramos fazer foi não desativar os programas centrais da Pró-Reitoria. Além disso, também podemos encontrar novas maneiras de realizar projetos. Os projetos de residência, por exemplo, podem ser mantidos através de bolsas de financiamento. A Pró-Reitoria sofre com as restrições orçamentárias, mas tem encontrado saídas para esta situação.

Suzana Helena de Avelar Gomes - Como a Pró-Reitoria de Cultura e Extensão interpreta o vínculo entre as áreas de humanas, ciências e tecnologia voltadas para a cultura e extensão?

MADNA - Acredito que o vínculo entre as áreas é absolutamente necessário. É preciso acabar com essa ideia de que uma universidade é, sobretudo, uma universidade das áreas técnicas ou das áreas experimentais. Não existe universidade sem uma vida cultural ou sem uma produção humanística de qualidade.

O modo de produção do trabalho intelectual é muito diversificado. Se você trabalha na área das ciências, por exemplo, a sua pesquisa é de um tipo, porque se você está em um laboratório, você tem uma teoria dominante e a sua pesquisa é ajustar o experimento à teoria dominante. Neste caso, observa-se em que medida aquele experimento a corrobora ou não, se pode alterar ou não a teoria dominante.

Não é o caso das humanidades, porque nós não temos uma teoria dominante. As nossas referências são muito fluídas e precisam ser primeiramente construídas. Por isso, é preciso construir um bom domínio teórico que irá ajudar o pesquisador na formulação de problemas. Trata-se de um processo demorado, que envolve pesquisas de diversas modalidades, inclusive as pesquisas quantitativas empíricas, em campo. Isso também significa que, por essa dimensão, as humanidades - e a partir delas eu posso pensar as outras - têm um compromisso de pensar mais globalmente. Então, devemos pensar, o que é a tecnologia? Não devemos esquecer que a técnica, sem a sua devida crítica, produziu barbárie.

Hoje fala-se muito em inovação: a Universidade tem que inovar. Mas o que é inovação na Universidade? Nós temos que responder essa pergunta. Então, veja, a inovação não é inovação em si mesma. Filosoficamente, a inovação está posta no século XVIII ligada à ideia do pensamento novo, em oposição ao passado. É a concepção moderna de mundo. Por isso, Hegel é o mais importante filósofo da modernidade. Ele constrói um pensamento auto-referido, voltado a si mesmo. Se a cultura moderna é a negação do passado e a ruptura com aquelas raízes, um pensamento circular, como é a dialética, é um pensamento sobretudo moderno, de rejeição do passado.

No século XIX temos algumas acepções do moderno, como, por exemplo, aquela ligada mais diretamente à produção, tal como tratado por Marx. $\mathrm{O}$ que é inovação nos termos do Marx? É o aumento da produtividade. E como aumentamos a produtividade? Faz-se isso pela alteração do processo de trabalho ou pela incorporação de novos meios de produção, novas tecnologias, de uma forma ou de outra, ou, comumente, pela combinação dos dois. Isso faz com que você produza muito mais em tempo igual, o que dá ganhos diferenciais ao dono do capital. A competição capitalista se faz segundo esse registro. A inovação aparece também como novo formulado no fenômeno das vanguardas modernas. É preciso ser absolutamente moderno.

Hoje existem várias acepções do novo, que agora entrou também no universo da Universidade. A Universidade tem que inovar. No geral, a noção de inovação que eu vejo na Universidade é a de que ela deve se transformar num braço de empresas produtivas e tecnológicas. Será essa a nossa acepção de inovação? Cabe a nós pensarmos o que é inovação na Universidade. Não é a mesma lógica da inovação tecnológica, com a finalidade de aumentar a produção para criar ganhos diferenciais. 
É claro que ela tem que ser, sim, inovadora: a Universidade tem que absorver e produzir de forma a colaborar com a mudança, com o aprimoramento da sociedade e o desenvolvimento para resolução de problemas sociais; ser braço de inovação de tecnologia para empresas, não. A Universidade é muito mais do que isso e, por esta razão, nós temos que fazer essa reflexão: o que é inovação no âmbito da Universidade? Eu tenho me proposto a pensar esse problema.

\section{BRP - A criação do Pólo Tecnológico pelo Governo} do Estado, ao lado da USP, sugere uma intensificação das relações culturais e de extensão entre exatas, humanas e biológicas. Qual a possibilidade e interesse da Pró-Reitoria de se envolver com o Pólo Tecnológico do Governo que envolve essas três grandes áreas?

MADNA - Temos disponibilidade, sim. Em primeiro lugar, porque a Pró-Reitoria tem que pensar essas questões. Em segundo lugar, isso é parte da difusão científica e da tecnologia. E a difusão da ciência, assim como a difusão da cultura, é um eixo de atuação da Pró-Reitoria de Cultura e Extensão Universitária. Então, o que cabe a Pró-Reitoria fazer? Não cabe à Pró-Reitoria ser apenas um braço da técnica para incentivar políticas de governo.

Não é possível esquecer que o pensamento brasileiro sempre estabeleceu uma relação de intimidade com o temário de desenvolvimento no Brasil. O sistema intelectual brasileiro se constituiu pensando no Brasil e por isso eu acredito que é nossa obrigação pensar o Brasil e não somente desenvolver uma tecnologia determinada para algum setor determinado, sem pensar o conjunto.

Ao mesmo tempo, cabe à Pró-Reitoria pensar essa tecnologia, por exemplo: qual o impacto da exploração de recursos naturais em uma determinada população? O que isso significa? O que é possível fazer? Quais são os processos educativos que cabem à extensão tratar? É importante a presença da Pró-Reitoria em tais iniciativas e eu estou absolutamente convencida de que esse é um bom momento para a área de cultura e extensão.
Diana Helena de Benedetto Pozzi - Qual pode ser a contribuição da cultura e extensão para o desenvolvimento de projetos Universidade-empresa?

MADNA - No campo da cultura e extensão, a empresa tem que assumir funções que estão além da dimensão cruamente ou restritamente empresarial. E isso é uma contribuição inexcedível da Pró-Reitoria de Cultura e Extensão, porque a empresa é um ambiente social, de convívio social e cultural. Não se imagina hoje uma empresa que seja absolutamente técnica ou produtiva. Ela tem que ter funções sociais muito bem definidas, as quais a Pró-Reitoria pode ajudar a pensar e construir.

DIANA HELENA DE BENEDETTO POZZI professora associada da Faculdade de Medicina da Universidade de São Paulo (FM-USP) e editora responsável da Revista de Cultura e Extensão USP - e-mail: revistacultext@usp.br

BRUNO ROBERTO PADOVANO professor titular da Faculdade de Arquitetura e Urbanismo da Universidade de São Paulo (FAU-USP) e editor associado da Revista de Cultura e Extensão USP

SUZANA HELENA DE AVELAR GOMES professora da Escola de Artes, Ciências e Humanidades da Universidade de São Paulo (EACH-USP) e editora associada da Revista de Cultura e Extensão USP

WALDENYR CALDAS professor titular da Escola de Comunicações e Artes da Universidade de São Paulo (ECA-USP) e editor associado da Revista de Cultura e Extensão USP

VERÔNICA CRISTO bacharel em Relações Públicas da Escola de Comunicações e Artes da Universidade de São Paulo (ECA-USP) e assistente editorial da Revista de Cultura e Extensão USP 